\title{
Clinical manifestations and outcome in Staphylococcus aureus endocarditis among injection drug users and nonaddicts: a prospective study of $\mathbf{7 4}$ patients
}

\author{
Eeva Ruotsalainen*1, Kari Sammalkorpi ${ }^{1}$, Janne Laine ${ }^{2}$, Kaisa Huotari ${ }^{1}$, \\ Seppo Sarna ${ }^{3}$, Ville Valtonen ${ }^{1}$ and Asko Järvinen ${ }^{1}$
}

Address: ${ }^{1}$ Division of Infectious Diseases, Department of Medicine, Helsinki University Central Hospital, Helsinki, Finland, ${ }^{2}$ Department of Medicine, Tampere University Hospital, Tampere, Finland and ${ }^{3}$ Department of Public Health, University of Helsinki, Helsinki, Finland

Email: Eeva Ruotsalainen* - eeva.ruotsalainen@hus.fi; Kari Sammalkorpi - kari.sammalkorpi@hus.fi; Janne Laine - janne.laine@tays.fi; Kaisa Huotari - kaisa.huotari@hus.fi; Seppo Sarna - seppo.sarna@helsinki.fi; Ville Valtonen - ville.valtonen@hus.fi; Asko Järvinen - asko.jarvinen@hus.fi

* Corresponding author

Published: II September 2006

BMC Infectious Diseases 2006, 6:137 doi:10.1 186/147|-2334-6-137
Received: II January 2006

Accepted: II September 2006

This article is available from: http://www.biomedcentral.com/I47I-2334/6/I37

(c) 2006 Ruotsalainen et al; licensee BioMed Central Ltd.

This is an Open Access article distributed under the terms of the Creative Commons Attribution License (http://creativecommons.org/licenses/by/2.0), which permits unrestricted use, distribution, and reproduction in any medium, provided the original work is properly cited.

\begin{abstract}
Background: Endocarditis is a common complication in Staphylococcus aureus bacteremia (SAB). We compared risk factors, clinical manifestations, and outcome in a large, prospective cohort of patients with S. aureus endocarditis in injection drug users (IDUs) and in nonaddicts.

Methods: Four hundred and thirty consecutive adult patients with $S A B$ were prospectively followed up for 3 months. Definite or possible endocarditis by modified Duke criteria was found in 74 patients: 20 patients were IDUs and 54 nonaddicts.

Results: Endocarditis was more common in $\mathrm{SAB}$ among drug abusers (46\%) than in nonaddicts (I4\%) (odds ratio [OR], 5.12; 95\% confidence interval [Cl], 2.65-9.9I; $P<0.001$ ). IDUs were significantly younger $(27 \pm 15$ vs $65 \pm 15$ years, $P<0.001)$, had less ultimately or rapidly fatal underlying diseases $(0 \%$ vs $37 \%, P<0.001)$ or predisposing heart diseases $(20 \%$ vs $50 \%, P=0.03)$, and their $\mathrm{SAB}$ was more often community-acquired ( $95 \%$ vs $39 \%, P<0.001$ ). Right-sided endocarditis was observed in $60 \%$ of IDUs whereas $93 \%$ of nonaddicts had left-sided involvement $(P<0.00 \mathrm{I})$. An extracardiac deep infection was found in $85 \%$ of IDUs and in $89 \%$ of nonaddicts $(P$ $=0.70$ ). Arterial thromboembolic events and severe sepsis were also equally common in both groups. There was no difference in mortality between the groups at 7 days, but at 3 months it was lower among IDUs (10\%) compared with nonaddicts (39\%) (OR, 5.73; $95 \% \mathrm{Cl}, 1.20-27.25 ; P=$ 0.02).

Conclusion: S. aureus endocarditis in IDUs was associated with as high complication rates including extracardiac deep infections, thromboembolic events, or severe sepsis as in nonaddicts. Injection drug abuse in accordance with younger age and lack of underlying diseases were associated with lower mortality, but after adjusting by age and underlying diseases injection drug abuse was not significantly associated with mortality.
\end{abstract}




\section{Background}

Bacteremic infections caused by Staphylococcus aureus have been reported with increasing frequency, and it has emerged as a leading cause of infective endocarditis (IE) in many regions of the world [1-3]. Endocarditis has been observed in $11 \%$ to $35 \%$ of $S$. aureus bacteremias (SAB) attributable to different sets of diagnostic criteria [4-6]. S. aureus endocarditis is associated with higher occurrence of extracardiac deep infections due to metastatic spread, thromboembolic complications, and a high mortality compared with IE caused by other pathogens $[1,2]$.

The incidence of endocarditis has not been changed during the past two decades $[7,8]$ but classic risk factors such as rheumatic heart disease are being replaced by new groups, including injection drug users (IDUs), elderly patients with degenerative valve disease, patients with intravascular catheter or prosthetic valve, and nosocomial acquisition $[2,3,8]$. One of the reasons for increased incidence of $S$. aureus in IE is injection drug abuse [9-11]. Colonization with $S$. aureus, HIV-related immunosuppression, female sex, increasing injection drug use frequency, and a history of previous IE are associated with a higher risk for endocarditis $[11,12]$.

Right-sided involvement, younger age, and lack of preexisting heart disease or other underlying diseases have been thought to explain the better prognosis of $S$. aureus endocarditis among IDUs than in general population $[2,13-15]$. Therefore, surgery is less frequently needed and shorter antibiotic courses have been used in IDUs [16,17]. Drug abusers tend to have fewer arterial embolic events or strokes than nonaddicts $[13,18]$. These differences between IDUs and general population have been derived from non-comparative trials, and there are only few studies where the clinical picture of $S$. aureus endocarditis in these patient groups has been compared [2,13,14,19].

We collected prospectively a large patient population with SAB and compared the risk factors, clinical, and echocardiographic findings as well as outcome of endocarditis in IDUs and in general population.

\section{Methods \\ Patient population}

Prospectively randomized adult patients with blood culture positive for $S$. aureus from 5 university hospitals and 7 tertiary care hospitals in Finland were taken into the trial from January 1999 to May 1999 and from January 2000 to August 2002. Originally, the trial was designed for evaluation on the effect of fluoroquinolone (trovafloxacin or levofloxacin) given in addition to most effective standard treatment in SAB [20] [see Additional file 1]. Clinical, pathological, and echocardiographic data of patients with definite or possible IE according to modified Duke criteria were collected [21], and these cases were included into the analysis. The protocol was approved by the ethics committees of all study sites, and written informed consent was obtained from all patients or their representatives. The trial was conducted in accordance with the Declaration of Helsinki.

The exclusion criteria were age younger than 18 years, imprisonment, proven or suspected pregnancy, breastfeeding, epilepsy, another bacteremia during the previous 28 days, polymicrobial bacteremia ( $\geq 3$ microbes), history of allergy to any quinolone antibiotic, previous tendinitis during fluoroquinolone therapy, prior fluoroquinolone use for more than 5 days before randomization, positive culture for $S$. aureus only from a central intravenous catheter, meningitis, neutropenia $\left(<0.5 \times 10^{9} / \mathrm{L}\right)$, or failure to supply an informed consent. Patients with bacteremia due to methicillin-resistant $S$. aureus (MRSA) and a $S$. aureus strain resistant to any fluoroquinolone were also excluded.

\section{Definitions}

IDUs were defined as patients who had injected drugs within the past 6 months before randomization. Routine bacteriological methods were used to detect $S$. aureus growth in blood [20] [see Additional file 1]. Bacteremia was hospital-acquired if the first positive blood culture was obtained $\geq 48$ hours after admission, or the patient was a resident in a long-term care facility or attended hemodialysis within the preceding 2 months. Prognosis or severity of underlying diseases were classified as healthy, nonfatal, ultimately, or rapidly fatal according to the criteria of McCabe and Jackson [22]. Severe sepsis at the time of first blood culture positive for $S$. aureus was defined as an infectious process leading to organ dysfunction or signs of hypoperfusion or hypotension [23].

The infection focus was documented by clinical, bacteriological, radiological, or pathological investigations. Intravenous catheter-associated bacteremia was defined using the guidelines of the Infectious Diseases Society of America [24]. Extracardiac deep infection was defined as pneumonia, deep-seated abscess, osteomyelitis, septic arthritis, meningitis, septic thrombophlebitis, mediastinitis, urinary tract infection, infection of any extracardiac prosthetic device, or recurrent SAB. Clinical findings of IE such as documentation of a new valvular regurgitant murmur, or evidence of any vascular phenomena such as infarction and embolic event or intracranial hemorrhage were detected. Endocarditis of prosthetic valve was classified as early when occurring $\leq 60$ days after valve replacement and as late $>60$ days after valve replacement. Leucocytosis was determined if white blood cell count was over $12 \times$ $10 \% / \mathrm{L}$ and leucopenia less than $4 \times 10^{9} / \mathrm{L}$. 


\section{Echocardiography}

Two-dimensional imaging from multiple tomographic planes and spectral Doppler and color flow imaging were used in all study sites. Transthoracic echocardiography (TTE) and/or transesophageal echocardiography (TEE) as clinically indicated were performed at the discretion of the treating physician and by experienced echocardiographers. The presence of cardiac vegetations, oscillation, paravalvular or intracardiac abscess, new valvular regurgitation, prosthetic valve dehiscence, and valve perforation were recorded [21].

\section{Antibiotic treatment}

The detailed information of the antimicrobial agents, doses, indications and duration of treatment have been described in our former article [20] [see Additional file 1]. All patients with endocarditis were assigned to receive initially cloxacillin or dicloxacillin ( $2 \mathrm{~g} \mathrm{q} 4 \mathrm{~h}$ ) for 4 to 6 weeks intravenously. Alternatively, cefuroxime (1.5 g q6 h) or vancomycin ( $1 \mathrm{~g}$ bid) were allowed if a contraindication against the use of semisynthetic penicillins was noted. Aminoglycoside (either tobramycin or netilmicin at $1 \mathrm{mg} /$ $\mathrm{kg}$ of body weight q8h) was added to the drug therapy described above for the first 7 days. Rifampicin (450 mg once daily for patients under $50 \mathrm{~kg}$ and $600 \mathrm{mg}$ once daily for patients over $50 \mathrm{~kg}$ in weight, orally or intravenously) was recommended for at least 4 weeks when an endocarditis or an extracardiac deep infection was suspected or confirmed. Half of the patients were randomized to receive a fluoroquinolone either trovafloxacin or levofloxacin in addition to therapy above. Fluoroquinolone treatment was not observed to have an impact on mortality in SAB or in patients with IE [20] [see Additional file $1]$. In cases of renal dysfunction the antibiotic doses were adjusted as recommended by the manufacturers.

\section{Clinical outcome}

All patients were prospectively followed for 3 months after the first positive blood culture for $S$. aureus. Case fatality rates were recorded at 7 days and 28 days, and at 3 months. Other outcome measures were site of valvular involvement, evidence of extracardiac deep infections or thromboembolic events, duration of fever (recorded in days until axillary temperature was $<37.5 \mathrm{C}^{\circ}$ ), duration of hospitalization and need for cardiac surgery. Laboratory tests were conducted on the day of the first positive blood culture for $S$. aureus.

\section{Statistical analysis}

Statistical analyses were performed with SPSS $^{\circledR}$ version 12.0. (SPSS Inc., Chicago, IL, USA). Univariate analyses for categorical variables were calculated with chi-square test or Fisher's exact test as appropriate, and for continuous variables the Mann-Whitney test was used. Odds ratios (OR) with $95 \%$ confidence intervals (CI) were as association measures. Cox regression analysis was used to compare survival of IDUs with nonaddicts, and results were given as hazard ratios (HR) with 95\% CI. Survival was calculated from the day of the first blood culture positive for $S$. aureus until 3 months. All tests were 2-tailed and $P$ values of $<0.05$ were considered significant.

\section{Results \\ Patient characteristics}

During the study period, 430 patients with $S$. aureus bacteremia were included into this trial. The included patients represented $31 \%$ of all SAB patients in study hospitals. Endocarditis was observed in 74 of 430 patients (17\%), of whom 20 were IDUs and 54 were nonaddicts. Thus, IE was observed in $46 \%$ of all 44 IDUs and in $14 \%$ of all 386 nonaddicts with SAB (OR, 5.12; 95\% CI, 2.65$9.91 ; P<0.001)$. Patients with endocarditis differed from those with SAB only by having significantly more often a predisposing heart disease or a pre-existing liver disease (chronic hepatitis $\mathrm{C}$ infection in 19 patients and hepatic cirrhosis in 5 patients), but less preceding trauma (Table 1). Other predisposing characteristics and underlying diseases of the patients with IE did not differ from those with SAB.

Among patients with endocarditis, IDUs as a group were younger and had less predisposing heart conditions, coronary artery disease or diabetes than nonaddicts (Table 2 ). When the underlying diseases were grouped by the predicted prognoses (McCabe's classification), none among the IDUs had a rapidly fatal or ultimately fatal disease but they were found in 20 of 54 nonaddicts (37\%) $(P$ $=0.001)$. However, there were three IDUs with HIV infection.

Only one drug abuser had a hospital-acquired bacteremia and none associated with the use of the central intravenous catheter (Table 2). Severe sepsis was observed in 9 of 20 IDUs (45\%) and in 28 of 54 nonaddicts (52\%) without significant difference between the groups $(P=0.79)$.

\section{Site of endocarditis}

According to the modified Duke criteria for endocarditis, 56 patients $(76 \%)$ were confirmed as definite ( 10 by pathologic criteria and 46 by clinical criteria), and 18 patients (24\%) as possible (Table 3). Left-sided involvement was observed in $93 \%$ of nonaddicts whereas in $60 \%$ of IDUs had right-sided endocarditis (tricuspid valve involvement in all patients). Among nonaddicts aortic valve was slightly more often involved (44\%) than mitral valve (35\%).

Prosthetic valve endocarditis, involving left side only, occurred in 17 of 74 patients (23\%) and they all presented 
Table I: Characteristics of $\mathbf{4 3 0}$ patients with Staphylococcus aureus bacteremia with and without endocarditis.

\begin{tabular}{|c|c|c|c|c|c|c|}
\hline Characteristic & $\begin{array}{l}\text { Bacteremia with endocarditis } \\
\qquad(n=74)\end{array}$ & $\begin{array}{l}\text { Bacteremia without endocarditis } \\
\qquad(n=356)\end{array}$ & $\begin{array}{c}\text { Total } \\
(n=430)\end{array}$ & OR & $95 \% \mathrm{Cl}$ & $P$ \\
\hline Age, mean years $\pm S D$ & $55 \pm 22$ & $59 \pm 17$ & $58 \pm 18$ & - & - & 0.26 \\
\hline Male sex & $47(64)$ & $221(62)$ & $268(62)$ & 1.06 & $0.63-1.79$ & 0.82 \\
\hline Hospital-acquired & $34(46)$ & $198(56)$ & $232(54)$ & 0.68 & $0.41-1.12$ & 0.13 \\
\hline Previous skin disease or wound & $34(46)$ & $189(53)$ & $223(52)$ & 0.75 & $0.45-1.24$ & 0.26 \\
\hline Previous surgery ${ }^{a}$ & $18(24)$ & $77(22)$ & $95(22)$ & 1.17 & $0.65-2.10$ & 0.61 \\
\hline Trauma in prior 2 months & $12(16)$ & $98(28)$ & $110(26)$ & 0.51 & $0.26-0.99$ & 0.04 \\
\hline Central intravenous catheter & $10(14)$ & $48(14)$ & $58(14)$ & 1.00 & $0.48-2.09$ & 0.99 \\
\hline Hemodialysis & $6(8)$ & $38(I I)$ & $44(10)$ & 0.74 & $0.30-1.82$ & 0.51 \\
\hline Previous S. aureus deep infection & $3(4)$ & $28(8)$ & $31(7)$ & 0.50 & $0.15-1.67$ & 0.33 \\
\hline Previous S. aureus bacteremia & $2(3)$ & $15(4)$ & $17(4)$ & 0.63 & $0.14-2.82$ & 0.75 \\
\hline Predisposing heart condition & $47(64)$ & $63(18)$ & $110(26)$ & 8.10 & $4.69-13.98$ & $<0.001$ \\
\hline Degenerative heart disease & $22(30)$ & $32(9)$ & $54(13)$ & 4.28 & $2.31-7.94$ & $<0.001$ \\
\hline Injection drug use & $20(27)$ & $24(7)$ & $44(10)$ & 5.12 & $2.65-9.91$ & $<0.001$ \\
\hline Prosthetic valve & $17(23)$ & $\mathrm{I}(0.3)$ & $18(4)$ & 105.88 & $|3.82-8| \mid .08$ & $<0.001$ \\
\hline Prior endocarditis & $11(15)$ & $0(0)$ & $11(3)$ & - & - & $<0.001$ \\
\hline Congenital heart disease & $5(7)$ & $5(1)$ & $10(2)$ & 5.09 & $1.43-18.05$ & 0.02 \\
\hline Mitral valve prolapse & $2(3)$ & $2(1)$ & $4(1)$ & 4.92 & $0.68-35.48$ & 0.14 \\
\hline Rheumatic heart disease & $2(3)$ & $\mathrm{I}(0.3)$ & $3(I)$ & 9.86 & $0.88-\mid 10.21$ & 0.08 \\
\hline Coronary artery disease & $21(28)$ & $89(25)$ & $110(26)$ & 1.19 & $0.68-2.08$ & 0.54 \\
\hline Corticosteroid use $\geq I$ month & $8(\mathrm{II})$ & $37(10)$ & $45(\mathrm{II})$ & 1.05 & $0.47-2.35$ & 0.92 \\
\hline Immunosuppressive therapy ${ }^{b}$ & $3(4)$ & $26(7)$ & $29(7)$ & 0.54 & $0.16-1.82$ & 0.45 \\
\hline Diabetes & $19(26)$ & $89(25)$ & $108(25)$ & 1.04 & $0.58-1.84$ & 0.90 \\
\hline Alcoholism & $4(5)$ & $44(12)$ & $48(\mathrm{II})$ & 0.41 & $0.14-1.17$ & 0.10 \\
\hline Liver disease & $24(32)$ & $43(12)$ & $67(16)$ & 3.49 & $1.95-6.25$ & $<0.001$ \\
\hline Malignancy & $9(12)$ & $54(15)$ & $63(15)$ & 0.77 & $0.36-1.65$ & 0.51 \\
\hline Chronic renal failure & $8(11)$ & $52(15)$ & $60(14)$ & 0.71 & $0.32-1.56$ & 0.39 \\
\hline HIV positive & $3(4)$ & $5(1)$ & $8(2)$ & 2.97 & $0.69-12.70$ & 0.14 \\
\hline
\end{tabular}

NOTE. Data are no. (\%) of patients, unless otherwise indicated.

a Includes cardiac and non-cardiac surgery during 3 months preceding the positive blood culture.

b During 6 months preceding the positive blood culture.

in nonaddicts. The most of these patients had an early onset of prosthetic valve IE (12 patients).

\section{Echocardiographic findings}

Echocardiography was performed in 263 of 430 patients (61\%) with SAB. Addicts underwent echocardiography significantly more often $(91 \%)$ compared with nonaddicts $(58 \%)(\mathrm{OR}, 7.31 ; 95 \% \mathrm{CI}, 2.56-20.84 ; P<0.001)$. In endocarditis, TTE was performed in 72 of 74 patients (97\%) with no significant difference between IDUs and nonaddicts (Table 3 ). TEE was performed significantly more often in nonaddicts than in IDUs ( $74 \%$ vs $45 \%$ ).

A vegetation was evident by echocardiography in $53 \%$ of cases and a new regurgitation in $71 \%$ of cases without significant differences between the groups (Table 3 ). Only 4 patients had an intracardial abscess or valve perforation.

\section{Clinical manifestations and outcome}

There were no differences in the clinical manifestations between the groups except the tendency for more frequent occurrence of various vascular phenomena among IDUs (Table 4). The most common infection focus was skin or soft tissue infection in 46 of 74 patients (62\%). An extracardiac deep infection was found in $85 \%$ of IDUs and in $89 \%$ of nonaddicts $(P=0.70)$.

Vascular complications, including arterial or venous thromboembolic events, were detected in $60 \%$ of IDUs but in only $35 \%$ of nonaddicts $(P=0.07)$ (Table 4$)$. Especially, septic pulmonary embolism was observed only in IDUs. Whereas all coronary artery related diseases were among nonaddicts, all 3 parenchymal embolic events were observed in drug abusers. Congestive heart failure in acute phase was present in 11 of 74 patients (15\%) with no difference between the groups. Two patients developed recurrent bacteremia during the 3 months follow-up period. There were no differences in median duration of fever ( 3 days) or median duration of hospitalization (32 days) between IDUs and nonaddicts (Table 5). Cardiac surgery was performed in $15 \%$ of IDUs but only in $7 \%$ of nonaddicts (OR, 2.21; 95\% CI, $0.45-10.87 ; P=0.38$ ).

Case fatality rate of all patients with IE was $23 \%$ at 28 days, and $31 \%$ at 3 months (Table 5). Mortality was significantly higher in nonaddicts than in addicts at 28 days 
Table 2: Characteristics of injection drug users and nonaddicts with Staphylococcus aureus endocarditis.

\begin{tabular}{|c|c|c|c|}
\hline Characteristic & $\begin{array}{l}\text { Injection drug users } \\
\qquad(n=20)\end{array}$ & $\begin{array}{l}\text { Nonaddicts } \\
(n=54)\end{array}$ & $P$ \\
\hline Age, mean years $\pm S D$ & $27 \pm 15$ & $65 \pm 15$ & $<0.001$ \\
\hline Male sex & $15(75)$ & $32(59)$ & 0.28 \\
\hline Hospital-acquired & I (5) & $33(61)$ & $<0.001$ \\
\hline Previous skin disease or wound & $12(60)$ & $22(4 I)$ & 0.19 \\
\hline Previous surgerya & $0(0)$ & $18(33)$ & 0.002 \\
\hline Trauma in prior 2 months & $3(15)$ & $9(17)$ & 1.00 \\
\hline Central intravenous catheter & $0(0)$ & $10(19)$ & 0.05 \\
\hline Hemodialysis & $0(0)$ & $6(11)$ & 0.18 \\
\hline Previous S. aureus deep infection & $2(10)$ & I (2) & 0.18 \\
\hline Previous S. aureus bacteremia & $2(10)$ & $0(0)$ & 0.07 \\
\hline Predisposing heart condition & $4(20)$ & $27(50)$ & 0.03 \\
\hline Degenerative heart disease & $0(0)$ & $22(4 I)$ & $<0.001$ \\
\hline Prosthetic valve & $0(0)$ & $17(32)$ & 0.004 \\
\hline Prior endocarditis & I (5) & $10(19)$ & 0.27 \\
\hline Congenital heart disease & $3(15)$ & $2(4)$ & 0.12 \\
\hline Mitral valve prolapse & $0(0)$ & $2(4)$ & 1.00 \\
\hline Rheumatic heart disease & $0(0)$ & $2(4)$ & 1.00 \\
\hline Coronary artery disease & $0(0)$ & $21(39)$ & $<0.001$ \\
\hline Corticosteroid use $\geq$ I month & $0(0)$ & $8(15)$ & 0.10 \\
\hline Immunosuppressive therapy ${ }^{b}$ & $0(0)$ & $3(6)$ & 0.56 \\
\hline Diabetes & $\mathrm{I}(5)$ & $18(33)$ & 0.02 \\
\hline Alcoholism & $0(0)$ & $4(7)$ & 0.57 \\
\hline Liver disease & $18(90)$ & $6(11)$ & $<0.001$ \\
\hline Chronic hepatitis C & $17(85)$ & $2(4)$ & $<0.001$ \\
\hline Hepatic cirrhosis & I (5) & $4(7)$ & 1.00 \\
\hline Malignancy & $0(0)$ & $9(17)$ & 0.10 \\
\hline Chronic renal failure & $0(0)$ & $8(15)$ & 0.10 \\
\hline HIV positive & $3(15)$ & $0(0)$ & 0.02 \\
\hline
\end{tabular}

NOTE. Data are no. (\%) of patients, unless otherwise indicated.

a Includes cardiac and non-cardiac surgery during 3 months preceding the positive blood culture.

b During 6 months preceding the positive blood culture.

(OR, 8.00; 95\% CI, 0.99-64.94; $P=0.03$ ), and also at 3 months (OR, 5.73; 95\% CI, 1.20-27.25; $P=0.02)$. Significant factors for lower mortality based on univariate analyses were injection drug abuse (HR, 0.22; 95\% CI, 0.05$0.92 ; P=0.04)$, age (HR, 1.03; 95\% CI, 1.01-1.06; $P=$ $0.006)$, and none or nonfatal underlying diseases by McCabe's classification (HR, 0.24; 95\% CI, 0.10-0.54; $P=$ $0.001)$. Statistically significant association for mortality were not found with the following: right-sided involvement (HR, 0.30; 95\% CI, 0.07-1.30; $P=0.11$ ), left-sided involvement (HR, 2.31; 95\% CI, 0.69-7.78; $P=0.18$ ), severe sepsis at the time of first positive blood culture for S. aureus (HR, $1.71 ; 95 \% \mathrm{CI}, 0.74-3.95 ; P=0.21$ ), or arterial embolic events (HR, 2.15; 95\% CI, 0.94-4.90; $P=$ 0.07). After adjusting by age and underlying diseases, injection drug abuse was not significantly associated with lower mortality (HR, 0.74; 95\% CI, 0.10-5.40; P = 0.77).

\section{Laboratory data}

At the time of first positive blood culture for $S$. aureus, leucocytosis was significantly more common in nonaddicts than in IDUs (55\% vs $15 \%$, respectively; $P=0.003$ ), and only 2 patients (4\%) had leucopenia. The median of serum C-reactive protein on the day of the first positive blood culture for $S$. aureus was $198 \mathrm{mg} / \mathrm{L}$ (range, 60-413 $\mathrm{mg} / \mathrm{L}$ ) in addicts compared with $171 \mathrm{mg} / \mathrm{L}$ (range, 5-478 $\mathrm{mg} / \mathrm{L}$ ) in nonaddicts without significant difference between the groups. Only 2 nonaddicts and none of IDUs had alanine aminotransferase level 2-fold above normal limit.

\section{Antibiotic treatment}

Sixty-five of 74 patients $(88 \%)$ were treated with cloxacillin or dicloxacillin with no significant difference between the groups. Seven patients (10\%) received cefuroxime, and one received vancomycin and one ceftriaxone. The median duration of parenteral antibiotic therapy from the first positive blood culture for $S$. aureus was 30 days (interquartile range, 24-43 days) in IDUs and 26 days (interquartile range, $13-34$ days $)$ in nonaddicts $(P=0.12)$, respectively.

An aminoglycoside was significantly more often given to addicts (19 of 20 patients) than to nonaddicts (29 of 54 
Table 3: Classification, valvular involvement and echocardiographic findings of injection drug users and nonaddicts with Staphylococcus aureus endocarditis.

\begin{tabular}{|c|c|c|c|c|c|c|}
\hline Variable & $\begin{array}{l}\text { Injection drug users } \\
\qquad(n=20)\end{array}$ & $\begin{array}{l}\text { Nonaddicts } \\
\quad(n=54)\end{array}$ & $\begin{array}{l}\text { Total } \\
(n=74)\end{array}$ & OR & $95 \% \mathrm{Cl}$ & $P$ \\
\hline \multicolumn{7}{|l|}{ Criteria, classification $^{a}$} \\
\hline Possible & I (5) & $17(32)$ & $18(24)$ & 0.12 & $0.01-0.93$ & 0.03 \\
\hline Definite & $19(95)$ & $37(69)$ & $56(76)$ & 8.73 & $1.08-70.67$ & 0.03 \\
\hline \multicolumn{7}{|l|}{ Valvular involvement ${ }^{\mathrm{b}}$} \\
\hline Left-sided & $6(30)$ & $50(93)$ & $56(76)$ & 0.03 & $0.01-0.14$ & $<0.001$ \\
\hline Aortic & $2(10)$ & $24(44)$ & $26(35)$ & 0.14 & $0.03-0.66$ & 0.006 \\
\hline Mitral & $3(15)$ & $19(35)$ & $22(30)$ & 0.33 & $0.08-1.25$ & 0.15 \\
\hline Aortic and mitral & I (5) & $7(13)$ & $8(11)$ & 0.35 & $0.04-3.07$ & 0.44 \\
\hline Right-sided & $12(60)$ & $4(7)$ & $16(22)$ & 18.75 & $4.83-72.73$ & $<0.001$ \\
\hline Both sides & $2(10)$ & $0(0)$ & $2(3)$ & - & - & 0.07 \\
\hline Echocardiography performed & $20(100)$ & $53(98)$ & $73(99)$ & - & - & 1.00 \\
\hline TTE & $20(100)$ & $52(96)$ & $72(97)$ & - & - & 1.00 \\
\hline TEE & $9(45)$ & $40(74)$ & $49(66)$ & 0.29 & $0.10-0.84$ & 0.03 \\
\hline \multicolumn{7}{|l|}{ Echocardiographyc } \\
\hline Vegetation & $14(70)$ & $25(47)$ & $39(53)$ & 0.26 & $0.87-7.84$ & 0.16 \\
\hline Regurgitation & $17(85)$ & $35(66)$ & $52(71)$ & 2.91 & $0.75-11.27$ & 0.15 \\
\hline Valve perforation & I (5) & $0(0)$ & $I(1)$ & - & - & 0.27 \\
\hline Paravalvular or intracardiac abscess & I (5) & $2(4)$ & $3(4)$ & 1.34 & $0.12-15.67$ & 1.00 \\
\hline Duration of bacteremia before diagnosis, median days (range) & $2(0-8)$ & $3(0-28)$ & $3(0-28)$ & - & - & 0.67 \\
\hline
\end{tabular}

NOTE. Data are no. (\%) of patients, unless otherwise indicated. TTE, transthoracic echogardiography; TEE, transesophageal echogardiography. a Classified by modified Duke criteria.

$\mathrm{b}$ Includes abnormal echocardiographic manifestations both in native valve or in prosthetic valve.

c Represents initial echocardiographic findings with TTE alone or with both TTE and TEE.

d Regurgitation observed on echocardiogram in any cardiac valve at the time of diagnosis of endocarditis.

patients) (OR, 16.38; 95\% CI, 2.05-131.21; $P=0.001)$. Eighteen of 20 IDUs (90\%) received rifampicin compared with 48 of 54 nonaddicts ( $89 \%$ ) with no significant difference between the groups.

\section{Discussion}

To the best of our knowledge, this trial is one of the largest prospective evaluations on $S$. aureus endocarditis comparing patients with and without injection drug use $[2,13]$. It is to be noted that our trial included only methicillin-sensitive $S$. aureus (MSSA) strains. MRSA strains are very rare in Finland ( $<2 \%$ from all isolated $S$. aureus strains) and not a single endocarditis due to MRSA had to be excluded. Lack of MRSA might complicate extrapolation of these results into countries with high MRSA prevalence. However, MRSA endocarditis is usually more difficult to treat. While concentrating only on cases caused by MSSA strains real differences between IDUs and nonaddicts might be better revealed. In our trial, right-sided involvement predominated slightly in IDUs whereas almost all nonaddicts had left-sided endocarditis. In contrast to previous data the frequency of complications among IDUs was equal to that among nonaddicts. An extracardiac deep infection was observed also in most of the addicts. According to recent studies, deep infections seem to be more common in SAB than previously thought $[20,25]$ [see Additional file 1]. In the current trial, the frequency of arterial embolic events was similar in both groups, although they have been observed less frequently among IDUs in earlier studies $[13,18,26]$. However, mortality in addicts was significantly lower than in nonaddicts as reported previously $[13,14,26,27]$.

S. aureus is an important and a more common cause of IE, especially among IDUs $[8,11]$. In a recent prospective multicenter study of 505 patients with SAB, endocarditis was found in $13 \%$ of all patients and in $35 \%$ of IDUs [6]. In agreement with that study, the incidence of IE was $17 \%$ among all SAB patients and 46\% among IDUs in our trial. The proportion of definite IE in the present trial $(76 \%)$ was also in line that observed in the other large survey [6].

Frequent use of echocardiography may increase the incidence of IE at least to some extent. Persistent bacteremia for over 3 days has been suggested to be a predictor for endocarditis [28] which was not designed for evaluation in our trial. We performed echocardiography as clinically indicated. It was done to $61 \%$ of SAB patients, and the rate was similar or higher compared with other studies $[19,25,29]$. Some endocarditis cases with atypical presentation might have been missed because echocardiography in our cohort as well as in previous studies was not performed for all SAB patients. The tricuspid valve was predominantly affected in addicts (60\%), although the 
Table 4: Clinical manifestations of injection drug users and nonaddicts with Staphylococcus aureus endocarditis during 3 months followup.

\begin{tabular}{|c|c|c|c|c|c|c|}
\hline Variable & $\begin{array}{l}\text { Injection drug users } \\
\qquad(n=20)\end{array}$ & $\begin{array}{l}\text { Nonaddicts } \\
\quad(n=54)\end{array}$ & $\begin{array}{c}\text { Total } \\
(n=74)\end{array}$ & OR & $95 \% \mathrm{Cl}$ & $P$ \\
\hline Skin or soft tissue & $12(60)$ & $34(63)$ & $46(62)$ & 0.88 & $0.31-2.53$ & 1.00 \\
\hline Central intravenous catheter & $0(0)$ & $3(6)$ & $3(4)$ & - & - & 0.56 \\
\hline Extracardiac deep infection ${ }^{\mathrm{a}}$ & $17(85)$ & $48(89)$ & $65(88)$ & 0.71 & $0.16-3.15$ & 0.70 \\
\hline Pneumonia & $14(70)$ & $27(50)$ & $41(55)$ & 2.33 & $0.78-6.98$ & 0.19 \\
\hline Deep-seated abscess ${ }^{b}$ & $7(35)$ & $25(46)$ & $32(43)$ & 0.63 & $0.22-|.8|$ & 0.44 \\
\hline Osteomyelitis & $6(30)$ & $17(32)$ & $23(31)$ & 0.93 & $0.31-2.85$ & 1.00 \\
\hline Septic arthritis & $3(15)$ & $5(9)$ & $8(11)$ & 1.73 & $0.37-8.02$ & 0.67 \\
\hline Urinary tract & I (5) & $4(7)$ & $5(7)^{\prime}$ & 0.66 & $0.07-6.27$ & 1.00 \\
\hline Recurrent S. aureus bacteremia & I (5) & I (2) & $2(3)$ & 2.79 & $0.17-46.84$ & 0.47 \\
\hline Mediastinitis & $0(0)$ & $9(17)$ & $9(12)$ & - & - & 0.10 \\
\hline Vascular phenomenon & $12(60)$ & $19(35)$ & $31(42)$ & 2.76 & $0.96-7.93$ & 0.07 \\
\hline Arterial thromboembolic event & $5(25)$ & $17(32)$ & $22(30)$ & 0.73 & $0.23-2.32$ & 0.78 \\
\hline Heartc & $0(0)$ & II (20) & $11(15)$ & - & - & 0.03 \\
\hline Spleen, kidney or liver & $3(15)$ & $0(0)$ & $3(4)$ & - & - & 0.02 \\
\hline Cerebral & $4(20)$ & 9 (I7) & $13(18)$ & 1.25 & $0.34-4.63$ & 0.74 \\
\hline Venous thromboembolic event & $8(40)$ & $4(7)$ & $12(16)$ & 8.33 & $2.15-32.32$ & 0.002 \\
\hline Pulmonary embolism ${ }^{\mathrm{d}}$ & $8(40)$ & $2(4)$ & $10(14)$ & 17.33 & $3.26-92.24$ & $<0.001$ \\
\hline Deep venous thrombosis & $0(0)$ & $2(4)$ & $2(3)$ & - & - & 1.00 \\
\hline
\end{tabular}

NOTE. Data are no. (\%) of patients, unless otherwise indicated.

a Each patient has been included once although some patients had several extracardiac deep infections at various time points.

b Intramuscular, epidural, cerebral, parenchymal, lung, peritoneal, subphrenic, gynecological and pericardial abscesses, or pleural empyema.

c Acute myocardial infarction or unstable angina.

d Includes 8 patients with septic pulmonary embolism and 2 patients with venous pulmonary embolism.

incidence was slightly lower than that reported previously (from $70 \%$ to $90 \%$ ) $[2,13,19,30]$. We presented that the frequency of left-sided involvement in addicts was as high as $30 \%$ which is similar to that in some studies $[2,10,31]$, but higher than in most earlier reports with left-sided endocarditis ranging from $8 \%$ to $19 \%[16,26,30]$. In IDUs, both sides of the heart are usually involved simultaneously in $5 \%$ to $10 \%$ of cases as detected in the current trial.

Extracardiac deep infections have been associated with $\mathrm{SAB}$ in left-sided endocarditis with the incidence ranging from $40 \%$ to $76 \%$ [20,32-34] [see Additional file 1]. In contrast to previous studies $[13,26,35]$, deep infections in our trial occurred in over $80 \%$ in both IDUs and nonaddicts. Systemic thromboembolic events are well recognized complications in endocarditis occurring in $21 \%$ to $50 \%$ of cases, especially in patients with left-sided involvement and prosthetic heart valves, and are accompanied by high mortality rates [36-39]. In earlier reports, IDUs had fewer arterial emboli or strokes than nonaddicts probably due to involvement of right-sided endocarditis $[2,18,40]$. In contrast, in our trial arterial thromboembolic events were observed with equal frequency in addicts and in nonaddicts. Venous embolic events were more common among addicts, and septic pulmonary embolism manifestated only in IDUs. However, the frequency of septic pulmonary embolism (40\%) was less than the previously reported incidence of $67 \%$ to $87 \%$ in IDUs [40-42].

Due to lack of controlled studies, indications for surgical approaches are not determined in patients with drug addiction [27]. Furthermore, doubts on compliance and continued drug abuse may reduce enthusiasm for surgery. Cardiac surgery is thought to be needed in only a small minority of cases in IDUs, and indications for surgical correction of right-sided involvement are not equally defined as for left-sided endocarditis $[16,41,43]$. However, some studies suggest that surgical treatment may clearly improve survival in IE among IDUs $[10,44]$. In this trial, cardiac surgery was as common in IDUs as in nonaddicts ( $15 \%$ vs $7 \%$ ), but valve repair was performed more often in addicts. The frequency of cardiac surgery in IDUs was high in light of prosthetic valve domination in nonaddicts in agreement with another recent study [2].

The duration of parenteral antibiotic treatment in SAB depends largely on the presence of an associated IE, in which 4 to 6 weeks therapy is recommended $[15,45,46]$. A shorter 2 weeks treatment has been suggested for selected cases of right-sided involvement with a good prognosis $[17,45]$. Recommendations on duration of aminoglycoside are variable. For left-sided native valve endocarditis 3-5 days therapy is suggested but as long as 2 weeks for right-sided involvement has been used 
Table 5: Outcome and surgical treatment of injection drug users and nonaddicts with Staphylococcus aureus endocarditis.

\begin{tabular}{|c|c|c|c|c|}
\hline Outcome & $\begin{array}{l}\text { Injection drug users } \\
\qquad(n=20)\end{array}$ & $\begin{array}{l}\text { Nonaddicts } \\
(n=54)\end{array}$ & $\begin{array}{l}\text { Total } \\
(n=74)\end{array}$ & $P$ \\
\hline \multicolumn{5}{|l|}{ Case fatality rate } \\
\hline At 7 days & I (5) & $6(11)$ & $7(9)$ & 0.67 \\
\hline At 28 days & I (5) & $16(30)$ & $17(23)$ & 0.03 \\
\hline At 3 months & $2(10)$ & $21(39)$ & $23(31)$ & 0.02 \\
\hline Duration of fever, median days (IQR) ${ }^{\mathrm{a}}$ & $3(2-10)$ & $3(0-6)$ & $3(1-6)$ & 0.24 \\
\hline Duration of hospitalization, median days (IQR) & $32(30-48)$ & $32(20-47)$ & $32(24-47)$ & 0.55 \\
\hline Cardiac surgery & $3(15)$ & $4(7)$ & $7(9)$ & 0.38 \\
\hline Valve replacement & I (5) & $4(7)$ & $5(7)$ & 1.00 \\
\hline Valve repairb & $3(15)$ & $0(0)$ & $3(4)$ & 0.02 \\
\hline
\end{tabular}

NOTE. Data are no. (\%) of patients, unless otherwise indicated. IQR, interquartile range.

${ }^{a}$ Fever $>37.5^{\circ} \mathrm{C}$ after the first positive blood culture for S. aureus with 72 patients ( 2 patients excluded, death before defervescence).

$\mathrm{b}$ Includes 2 patients with vegetectomy and I patient with annuloplasty.

$[47,48]$. In addition, two small studies have demonstrated oral fluoroquinolone and rifampicin for 4 weeks to be as effective as the standard intravenous therapy in rightsided endocarditis $[49,50]$. In our cohort, the high proportion of extracardiac deep infections in addicts extended the intravenous antibiotic therapy to 4 weeks. This observation suggest that deep infections should be actively searched for also among IDUs.

This trial was not designed to reveal possible differences between antibiotic treatments and the statistical power would neither enable such analysis. However, in accordance with positive results in experimental and animal studies we found lower mortality in SAB with a deep infection when the patients were treated with rifampicin in addition to standard treatment [20] [see Additional file 1]. In the present trial, most IDUs were also treated with rifampicin which might cause problems with drug interactions not least with methadone.

Overall mortality rate was significantly higher among nonaddicts $(39 \%)$ than in addicts $(10 \%)$ in accordance with $30 \%$ to $70 \%$ mortality previously reported in nonaddicts $[1,5,14]$. In earlier studies, poor prognosis has been associated with left-sided involvement, endocarditis of prosthetic valve, higher incidence of underlying diseases, central nervous system manifestations, and older age $[1,14,19,29]$. Our trial showed that injection drug abuse in accordance with younger age and lack of severe underlying diseases were associated with better prognosis. There was a tendency for lower mortality in patients with rightsided IE but for higher mortality in patients with severe sepsis, left-sided involvement, and arterial embolic events. However, these factors did not achieve statistical significance probably due to insufficient sample size.

\section{Conclusion}

We concluded that endocarditis was more frequently connected to SAB among IDUs. In contrast to previous reports, addicts had equally often complications including extracardiac deep infections and arterial thromboembolic events as nonaddicts. In spite of this, mortality was significantly lower in IDUs in accordance with earlier data.

\section{Competing interests}

Financial competing interests: ER has served as consultant to Aventis Pharma. AJ and VV have been consultants to several companies including Aventis Pharma, Bayer, Pfizer Inc., AstraZeneca, Roche, Pharmacia and Merck \& $\mathrm{Co}$, Inc. None of the authors had non-financial competing interests to disclose.

\section{Authors' contributions}

Authors ER, KS, JL, VV, and AJ participated in the design and coordination of the study. ER, KS, and JL made substantial contributions to acquisition of data. ER, KH, SS, $\mathrm{VV}$, and AJ performed statistical analysis. All authors read and approved the final manuscript.

\section{Additional material}

\section{Additional file 1 \\ Levofloxacin does not decrease mortality in Staphylococcus aureus bacteraemia when added to the standard treatment: A prospective and randomized clinical trial of 381 patients. This article represents original trial where the effect of levofloxacin in addition to standard antistaphylo- coccal treatment of $S A B$ was studied in relation to patient outcome and development of complications. \\ Click here for file \\ [http://www.biomedcentral.com/content/supplementary/1471- 2334-6-137-S1.pdf]}

\section{Acknowledgements}

We thank the FINLEVO study group investigators for their invaluable participation in patient collection [see Additional file I]. This study was supported by an unrestricted grant (ER, VV, and $\mathrm{A} J$ ) from Aventis Pharma and 
Pfizer Inc., and a grant from the special Finnish governmental subsidy for health sciences research (ER and $\mathrm{AJ}$ ).

\section{References}

I. Miro JM, Anguera I, Cabell CH, Chen AY, Stafford JA, Corey GR, Olaison L, Eykyn S, Hoen B, Abrutyn E, Raoult D, Bayer A, Fowler $V G$ : Staphylococcus aureus native valve infective endocarditis: report of $\mathbf{5 6 6}$ episodes from the International Collaboration on Endocarditis Merged Database. Clin Infect Dis 2005, 4l:507-5I4.

2. Fowler VG], Miro JM, Hoen B, Cabell CH, Abrutyn E, Rubinstein E Corey GR, Spelman D, Bradley SF, Barsic B, Pappas PA, Anstrom KJ, Wray D, Fortes CQ, Anguera I, Athan E, Jones P, van der Meer JT, Elliott TS, Levine DP, Bayer AS: Staphylococcus aureus endocarditis: a consequence of medical progress. Jama 2005, 293:3012-3021.

3. Mylonakis $E$, Calderwood SB: Infective endocarditis in adults. $N$ Engl J Med 2001, 345:1318-1330.

4. Mirimanoff RO, Glauser MP: Endocarditis during Staphylococcus aureus septicemia in a population of non-drug addicts. Arch Intern Med 1982, I42:131|-1313.

5. Hedstrom SA, Christensson B: Staphylococcus aureus septicaemia and endocarditis at the University Hospital in Lund 1 976-1980. Scand J Infect Dis Suppl 1983, 41:38-48.

6. Chang FY, MacDonald BB, Peacock JEJ, Musher DM, Triplett $P$ Mylotte JM, O'Donnell A, Wagener MM, Yu VL: A prospective multicenter study of Staphylococcus aureus bacteremia: incidence of endocarditis, risk factors for mortality, and clinical impact of methicillin resistance. Medicine (Baltimore) 2003, 82:322-332

7. Cecchi E, Forno D, Imazio M, Migliardi A, Gnavi R, Dal Conte I, Trinchero R: New trends in the epidemiological and clinical features of infective endocarditis: results of a multicenter prospective study. Ital Heart J 2004, 5:249-256.

8. Moreillon P, Que YA: Infective endocarditis. Lancet 2004, 363:139-149.

9. Bassetti $S$, Battegay $M$ : Staphylococcus aureus infections in injection drug users: risk factors and prevention strategies. Infection 2004, 32:163-169.

10. Mathew J, Addai T, Anand A, Morrobel A, Maheshwari P, Freels S: Clinical features, site of involvement, bacteriologic findings, and outcome of infective endocarditis in intravenous drug users. Arch Intern Med 1995, I 55:1641-1648.

II. Wilson LE, Thomas DL, Astemborski J, Freedman TL, Vlahov D: Prospective study of infective endocarditis among injection drug users. J Infect Dis 2002, I 85: I76I-1766.

12. Gordon RJ, Lowy FD: Bacterial infections in drug users. N Engl J Med 2005, 353:1945-1954

13. Chambers HF, Korzeniowski OM, Sande MA: Staphylococcus aureus endocarditis: clinical manifestations in addicts and nonaddicts. Medicine (Baltimore) 1983, 62:170-177.

14. Julander I: Unfavourable prognostic factors in Staphylococcus aureus septicemia and endocarditis. Scand J Infect Dis 1985 | 7:179-187.

15. Karchmer AW: Infective endocarditis. In Heart Disease: A Textbook of Cardiovascular Medicine 6th edition. Edited by: Braunwald E, Zipes DP, Libby P. WB Saunders Company: Philadelphia; 200I:I723-1750.

16. Miro JM, del Rio A, Mestres CA: Infective endocarditis and cardiac surgery in intravenous drug abusers and HIV-I infected patients. Cardiol Clin 2003, 2 I: 167-84, v-vi.

17. Torres-Tortosa M, de Cueto M, Vergara A, Sanchez-Porto A, PerezGuzman E, Gonzalez-Serrano M, Canueto J: Prospective evaluation of a two-week course of intravenous antibiotics in intravenous drug addicts with infective endocarditis. Grupo de Estudio de Enfermedades Infecciosas de la Provincia de Cadiz. Eur J Clin Microbiol Infect Dis 1994, I 3:559-564.

18. Hart RG, Foster JW, Luther MF, Kanter MC: Stroke in infective endocarditis. Stroke 1990, 21:695-700.

19. Watanakunakorn C: Staphylococcus aureus endocarditis at a community teaching hospital, 1980 to 1991. An analysis of I 06 cases. Arch Intern Med 1994, I 54:2330-2335.

20. Ruotsalainen E, Järvinen A, Koivula I, Kauma $H$, Rintala E, Lumio J, Kotilainen P, Vaara M, Nikoskelainen J, Valtonen V: Levofloxacin does not decrease mortality in Staphylococcus aureus bacteraemia when added to the standard treatment: a prospective and randomized clinical trial of $38 \mathrm{I}$ patients. J Intern Med 2006, 259:179-190.

21. Li JS, Sexton DJ, Mick N, Nettles R, Fowler VGJ, Ryan T, Bashore T, Corey GR: Proposed modifications to the Duke criteria for the diagnosis of infective endocarditis. Clin Infect Dis 2000, 30:633-638.

22. McCabe WR, Jackson GG: Gram negative bacteraemia I. Etiology and ecology. Arch Intern Med 1962, I I 0:847-855.

23. Levy MM, Fink MP, Marshall JC, Abraham E, Angus D, Cook D, Cohen J, Opal SM, Vincent JL, Ramsay G: 200I SCCM/ESICM/ACCP/ ATS/SIS International Sepsis Definitions Conference. Crit Care Med 2003, 3 I: I 250-I256.

24. Mermel LA, Farr BM, Sherertz RJ, Raad II, O'Grady N, Harris JS, Craven $D E$ : Guidelines for the management of intravascular catheter-related infections. Clin Infect Dis 200I, 32: I 249-I 272.

25. Fowler VGJ, Olsen MK, Corey GR, Woods CW, Cabell CH, Reller LB, Cheng AC, Dudley T, Oddone EZ: Clinical identifiers of complicated Staphylococcus aureus bacteremia. Arch Intern Med 2003, 163:2066-2072.

26. Levine DP, Crane LR, Zervos MJ: Bacteremia in narcotic addicts at the Detroit Medical Center. II. Infectious endocarditis: a prospective comparative study. Rev Infect Dis 1986, 8:374-396.

27. Moss $R$, Munt $B$ : Injection drug use and right sided endocarditis. Heart 2003, 89:577-581.

28. Khatib R, Johnson LB, Fakih MG, Riederer K, Khosrovaneh A, Shamse Tabriz M, Sharma M, Saeed S: Persistence in Staphylococcus aureus bacteremia: Incidence, characteristics of patients and outcome. Scand J Infect Dis 2006, 38:7-I4

29. Mylotte JM, Tayara A: Staphylococcus aureus bacteremia: predictors of 30-day mortality in a large cohort. Clin Infect Dis 2000, $31:$ : I 170-1174.

30. Julander I: Staphylococcal septicaemia and endocarditis in $\mathbf{8 0}$ drug addicts. Aspects on epidemiology, clinical and laboratory findings and prognosis. Scand J Infect Dis Suppl I983, 41:49-55.

31. Graves MK, Soto L: Left-sided endocarditis in parenteral drug abusers: recent experience at a large community hospital. South Med J 1992, 85:378-380.

32. Bayer AS, Lam K, Ginzton L, Norman DC, Chiu CY, Ward Jl: Staphylococcus aureus bacteremia. Clinical, serologic, and echocardiographic findings in patients with and without endocarditis. Arch Intern Med 1987, 147:457-462.

33. Fowler VGJ, Schelenz S, Bayer AS: Endocarditis and intravascular infections. In Mandell, Douglas and Bennett's Principles and Practice of Infectious Diseases. Volume 2 6th edition. Edited by: Mandell GL, Bennett JE, Dolin R. Philadelphia: Churchill Livingstone; 2005:975-102I.

34. Fowler VG], Sanders LL, Kong LK, McClelland RS, Gottlieb GS, Li J, Ryan T, Sexton DJ, Roussakis G, Harrell LJ, Corey GR: Infective endocarditis due to Staphylococcus aureus: $\mathbf{5 9}$ prospectively identified cases with follow-up. Clin Infect Dis 1999, 28:106-1 |4.

35. Ringberg $H$, Thoren A, Lilja B: Metastatic complications of Staphylococcus aureus septicemia. To seek is to find. Infection 2000, 28: I32-136.

36. Baddour LM, Bisno AL: Infective endocarditis complicating mitral valve prolapse: epidemiologic, clinical, and microbiologic aspects. Rev Infect Dis 1986, 8: II7-I37.

37. Fabri JJ, Issa VS, Pomerantzeff PM, Grinberg M, Barretto AC, Mansur AJ: Time-related distribution, risk factors and prognostic influence of embolism in patients with left-sided infective endocarditis. Int J Cardiol 2006, I I 0:334-339.

38. Hasbun R, Vikram HR, Barakat LA, Buenconsejo J, Quagliarello VJ: Complicated left-sided native valve endocarditis in adults: risk classification for mortality. JAMA 2003, 289:1933-1940.

39. Thuny F, Disalvo G, Belliard O, Avierinos JF, Pergola V, Rosenberg V, Casalta JP, Gouvernet J, Derumeaux G, larussi D, Ambrosi P, Calabro R, Riberi A, Collart F, Metras D, Lepidi H, Raoult D, Harle JR, Weiller PJ, Cohen A, Habib G: Risk of embolism and death in infective endocarditis: prognostic value of echocardiography: a prospective multicenter study. Circulation 2005, I | 2:69-75.

40. Hecht SR, Berger M: Right-sided endocarditis in intravenous drug users. Prognostic features in $\mathbf{1 0 2}$ episodes. Ann Intern Med 1992, I I 7:560-566.

4I. Bouza E, Menasalvas A, Munoz P, Vasallo FJ, del Mar Moreno M, Garcia Fernandez MA: Infective endocarditis-a prospective study at the end of the twentieth century: new predisposing condi- 
tions, new etiologic agents, and still a high mortality. Medicine (Baltimore) 200I, 80:298-307.

42. Sklaver AR, Hoffman TA, Greenman RL: Staphylococcal endocarditis in addicts. South Med J I 978, 7 I:638-643.

43. Faber M, Frimodt-Moller N, Espersen F, Skinhoj P, Rosdahl V: Staphylococcus aureus endocarditis in Danish intravenous drug users: high proportion of left-sided endocarditis. Scand J Infect Dis 1995, 27:483-487.

44. Arbulu A, Holmes RJ, Asfaw I: Surgical treatment of intractable right-sided infective endocarditis in drug addicts: 25 years experience. J Heart Valve Dis 1993, 2:129-37; discussion I38-9.

45. Baddour LM, Wilson WR, Bayer AS, Fowler VG], Bolger AF, Levison ME, Ferrieri P, Gerber MA, Tani LY, Gewitz MH, Tong DC, Steckelberg JM, Baltimore RS, Shulman ST, Burns JC, Falace DA, Newburger JW, Pallasch TJ, Takahashi M, Taubert KA: Infective endocarditis: diagnosis, antimicrobial therapy, and management of complications: a statement for healthcare professionals from the Committee on Rheumatic Fever, Endocarditis, and Kawasaki Disease, Council on Cardiovascular Disease in the Young, and the Councils on Clinical Cardiology, Stroke, and Cardiovascular Surgery and Anesthesia, American Heart Association: endorsed by the Infectious Diseases Society of America. Circulation 2005, I I I:e394-434.

46. Moreillon P, Que YA, Glauser MP: Staphylococcus aureus (including staphylococcal toxic shock). In Mandell, Douglas, and Bennett's Principles and Practice of Infectious Diseases. Volume 2 6th edition. Edited by: Mandell GL, Bennett JE, Dolin R. Philadelphia: Churchill Livingstone; 2005:232I-235I.

47. Lowy FD: Staphylococcus aureus infections. N Engl J Med 1998, 339:520-532.

48. Petti CA, Fowler VG]: Staphylococcus aureus bacteremia and endocarditis. Infect Dis Clin North Am 2002, 16:41 3-435.

49. Heldman AW, Hartert TV, Ray SC, Daoud EG, Kowalski TE, Pompili V], Sisson SD, Tidmore WC, vom Eigen KA, Goodman SN, Lietman PS, Petty BG, Flexner C: Oral antibiotic treatment of rightsided staphylococcal endocarditis in injection drug users: prospective randomized comparison with parenteral therapy. Am J Med 1996, I01:68-76.

50. Dworkin RJ, Lee BL, Sande MA, Chambers HF: Treatment of rightsided Staphylococcus aureus endocarditis in intravenous drug users with ciprofloxacin and rifampicin. Lancet 1989, 2:1071-1073.

\section{Pre-publication history}

The pre-publication history for this paper can be accessed here:

http://www.biomedcentral.com/1471-2334/6/137/pre

pub

\section{Publish with Bio Med Central and every scientist can read your work free of charge}

"BioMed Central will be the most significant development for disseminating the results of biomedical research in our lifetime. "

Sir Paul Nurse, Cancer Research UK

Your research papers will be:

- available free of charge to the entire biomedical community

- peer reviewed and published immediately upon acceptance

- cited in PubMed and archived on PubMed Central

- yours - you keep the copyright

Submit your manuscript here:

http://www.biomedcentral.com/info/publishing_adv.asp
BioMedcentral 